\title{
The current state of engineered nanomaterials in consumer goods and waste streams: the need to develop nanoproperty-quantifiable sensors for monitoring engineered nanomaterials
}

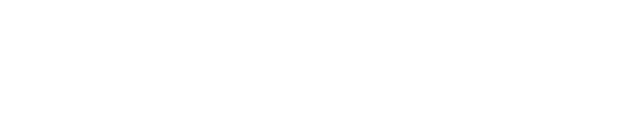

\author{
Kelsey Wise \\ Murphy Brasuel \\ Department of Chemistry and \\ Biochemistry, Colorado College, \\ Colorado Springs, CO, USA
}

Correspondence: Murphy Brasuel Department of Chemistry and Biochemistry, Colorado College, 14 East Cache La Poudre Street, Colorado Springs,

CO 80903-3298, USA

$\mathrm{Tel}+\mathrm{I} 7192278256$

Fax +I 7193896183

Email mbrasuel@coloradocollege.edu

\begin{abstract}
As nanomaterials are harnessed for medicine and other technological advances, an understanding of the toxicology of these new materials is required to inform our use. This toxicological knowledge will be required to establish the medical and environmental regulations required to protect consumers and those involved in nanomaterial manufacturing. Nanoparticles of titanium oxide, carbon nanotubes, semiconductor quantum dots, gold, and silver represent a high percentage of the nanotechnology currently available or currently poised to reach consumers. For these nanoparticles, this review aims to identify current applications, the current methods used for characterization and quantification, current environmental concentrations (if known), and an introduction to the toxicology research. Continued development of analytical tools for the characterization and quantification of nanomaterials in complex environmental and biological samples will be required for our understanding of the toxicology and environmental impact of nanomaterials. Nearly all materials exhibit toxicity at a high enough concentration. Robust, rapid, and cost effective analytical techniques will be required to determine current background levels of anthropogenic, accidental, and engineered nanoparticles in air, water, and soil. The impact of the growing number of engineered nanoparticles used in consumer goods and medical applications can then be estimated. This will allow toxicological profiles relevant to the demonstrated or predicted environmental concentrations to be determined.
\end{abstract}

Keywords: titanium dioxide nanoparticles, carbon nanotubes, semiconductor quantum dots, gold nanoparticles, silver nanoparticles, nanoparticles environmental concentrations

\section{Introduction}

Nanotechnology, a technological advance accelerating technology that cuts across an array of industrial sectors, is a rapidly growing field of science that could potentially revolutionize our world economy. Nanotechnology involves materials 1-100 nm, which are particles that are effectively a bridge between atomic or molecular structures and bulk materials. These particles have novel properties resulting from nanomaterials' large surface area per unit of volume and the quantum effects that occur at the nanometer scale. Physical and chemical behavior that are a direct result of their size include color, thermal behavior, material strength, solubility, conductivity, and catalytic activity. ${ }^{1}$ Technological enhancements include greater catalytic efficiency, increased electrical conductivity, and improved hardness and strength. ${ }^{2}$

Nanotechnology will lead to cellular building materials, disaster-resistant materials, intelligent materials, superior insulating materials, ultraviolet (UV)-resistant paint 
coatings, and new medical technology. ${ }^{2}$ While there are few agencies that require the reporting of nanomaterial components in consumer goods. The Project on Emerging Nanotechnologies (established in April of 2005) by the Woodrow Wilson International Center for Scholars and the Pew Charitable Trusts works on maintaining an inventory of consumer goods containing nanomaterials either identified by the manufacturer or through a combination of other sources. The number of identified consumer products grew at an average rate $43 \%$ between 2007 and 2009 with 1500 products predicted to have nanomaterials by $2011 .{ }^{3}$ Rapid developments in nanotechnology are enabling rapid advances in multiple technological fields. The end result will be a continued growth in the number of consumer products containing nanotechnology.

Continued investment in fundamental research on nanotechnology has resulted in the rapid discovery of unique physical and chemical properties of nanomaterials that have applications in everything from medicine to renewable energy. Multiple nanomaterials have shown medical promise in applications ranging from drug delivery to cancer therapy. More work must be done on determining the end fate of the nanoparticles following therapy. ${ }^{4}$ It is not difficult to find a review that covers the potential of a specific nanomaterial for a given application. The funding for research in medicine and medical devices has resulted in numerous studies of the technological advantages nanotechnology can bring to this field. In the medical field the unique characteristics of gold nanoparticles have been harnessed for drug delivery, ${ }^{5,6}$ for use as a contrast enhancer in medical imaging, ${ }^{7,8}$ for use in cancer and gene therapy, ${ }^{6,8}$ and for use in pathogen detection in water, as well as water purification. ${ }^{9}$

Other prominent inorganic nanoparticles include titanium oxide, zinc oxide, iron oxide, silica, and a host of inorganic semiconductors. Titanium dioxide has proven potential in solar cells, ${ }^{10}$ fuel cells, ${ }^{11}$ and hydrogen production. ${ }^{12}$ Nanoparticles of titanium dioxide are widely available to the consumer in the form of an active ingredient in sunscreens where it serves as a UV absorber, as pigment in toothpaste and foodstuff, ${ }^{3,13}$ and in products that use the photocatalytic properties of titanium dioxide to break down organic materials, like self-cleaning windows. ${ }^{3,14}$

Nanoparticles of iron oxide show promise as a contrast agent in cancer diagnosis, and as a component of multifunctional particles for diagnosis and treatment of cancer. ${ }^{7,15-18}$ Silica-based nanoparticles have applications in the improvement of the specificity and efficacy of photodynamic therapy, ${ }^{19}$ and drug delivery. ${ }^{20}$ Silica nanoparticles have also been used to develop targeted contrast agents, small-molecule sensors, platforms for gene delivery, ${ }^{21}$ and platforms for specific catalysis (which can be applied to renewable energy conversion in the splitting of water and carbon dioxide). ${ }^{22}$ The semiconductor nanostructures quantum dots have been demonstrated as advantageous in biological imaging for medical diagnosis, ${ }^{7,8,17,23}$ solar energy conversion, ${ }^{24}$ and in the catalytic splitting of water. ${ }^{25}$

There is a wide range of organic nanoparticles. A few examples of their use in medicine include lipid nanoparticles and carbon nanotubes for drug delivery, ${ }^{26-29}$ for food fortification, ${ }^{30}$ carbon nanotubes for cancer therapy, ${ }^{8,31}$ and carbon nanotubes as structural components of complex nanomedical systems. ${ }^{32}$

The uses referenced above are not meant to be an exhaustive compilation of the potential nanotechnology has to impact society; it is meant to merely be a glimpse of the potential that nanotechnology has shown in the high profile fields of medicine and renewable energy. The 1015 nanomaterials containing consumer products identified as of August, 2009 by The Project on Emerging Nanotechnologies is just the start of what will be an exponential growth in availability. The far reaching uses of nanotechnology dictate that this will be the case. The unique properties of nanomaterials will be harnessed to advance all applicable fields. At the same time we should be conscious that the unique properties of nanomaterials that can be harnessed for advances have the potential to exhibit unique toxicity profiles in the body and in the environment.

The rapid growth of nanotechnology research and the resultant potential for nanotechnology's rapid entrance into consumer goods presents a challenge to the regulatory agencies in health, food, and environmental protection. Two of these agencies are the United States (US) Food and Drug Administration (FDA) and the Environmental Protection Agency. Nanomaterials have already reached the consumer market and rapid growth in consumer available nanomaterials is expected. Some of the materials with useful properties in the nanodomain have already been deemed as safe by regulatory agencies in the bulk form. To allow the nanomaterial into consumer goods if the bulk form has been deemed safe is to ignore the unique physical and chemical characteristics that are realized with nanomaterials. The unique physical and chemical properties that make nanomaterials attractive for materials applications may also have unintended environmental and biological side effects. In order to regulate nanomaterials that may have detrimental impacts on human and environmental health, analytical methods are needed to identify nanomaterials present in environmental and biological systems. ${ }^{33,34}$ 
These methods need to be able to specifically identify nanomaterials, because it has been proven that molecular and bulk form of materials containing the same elemental profile will have different physical and chemical properties. In order to achieve a realistic scope, this review will focus on analytical methods for the identification and characterization of nanomaterials that are currently present in commercial goods, or have the potential to be present in the short term. It would be a disservice to over generalize properties of nanomaterials because of the wide variation of properties exhibited by different materials and wide variation of the impact of size on the properties of different materials. ${ }^{35,36} \mathrm{We}$ will describe nanomaterials that currently (or will potentially soon) appear in consumer goods, the studies that point to their safety or potential toxicity, methods for determining their presence in environmental samples or biological systems, and the current environmental concentrations if applicable. Tiede et al have reviewed all of the techniques that have the potential to be harnessed for nanoparticle detection and characterization in environmental and food samples; ${ }^{1,37}$ the aim of this document is to review techniques actively being used for the analysis of engineered nanoparticles that consumers have the potential to be exposed to now or in the near future.

Little is known about the occurrence, fate, and toxicity of nanoparticles, partially because of the lack of methodology for the detection and characterization of nanoparticles in complex matrices (water, soil, or food). ${ }^{1}$ However, there are a few procedures available. It is of emerging concern that nanomaterials are able to reach aquatic environments, and it is essential to be able to filter nanomaterials from complex water matrices. Titanium-, carbon-, and silver-based nanomaterials currently are the most widely referenced components of nanomaterials available to consumers. Silver nanoparticles are by far the most available nanoparticles in consumer goods. ${ }^{3}$ We will review these materials as well as semiconductor quantum dots due to the commercial availability of quantum dots and their potential to find use both in medical applications as well as renewable energy. Table 1 summarizes current environmental concentrations of these nanomaterials (if known), expected concentrations based on models, as well as concentrations used in some assays of toxicology.

\section{Use, toxicology, and environmental concentrations of selected nanoparticles Titanium dioxide}

Titanium dioxide nanoparticles are present in a number of consumer goods. This mineral is the most widely used white pigment as a result of its brightness and high refractive index. It is used to provide whiteness and opacity in toothpastes, foods, papers, plastics, and paints. ${ }^{2}$ Titanium dioxide is also a component of many cosmetic and skin care products, and is present in most sunscreens, as it provides great protection from UV rays. One way nano titanium dioxide is distinguished from titanium dioxide in bulk is that it scatters very little visible light and appears transparent on the skin. ${ }^{38}$ Nano titanium dioxide is thus chosen as a component of sunscreen to provide protection from UV rays as it does not result in an unsightly opaque layer on the skin.

Nano titanium is also used as a component of self-cleaning windows. The absorption of UV light in the presence of oxygen results in reactive oxygen species that break down organic compounds. ${ }^{3,14}$ The reactivity of nano titanium dioxide has resulted in concern by consumer groups over potential toxicity due to the release of the titanium dioxide nanoparticles into the environment or the internalization of nanoparticles by consumers using skin care, food, or cosmetic products containing this compound. ${ }^{39}$ The challenge for developing realistic regulation and toxicological studies are the lack of widely used methods for the determination of titanium dioxide nanoparticles size distributions and concentrations in biological and environmental samples. To fill this gap Gottschalk et $\mathrm{al}^{40}$ and Muller and Nowack ${ }^{41}$ have modeled exposure and environmental concentrations of titanium dioxide as well as some other nanoparticles (zinc oxide, silver, carbon nanotubes, fullerenes). The lack of reliable data from environmental surveys resulted in the worst case scenarios being used in the modeling of the potential concentrations of nano titanium dioxide in the environment. These models predict that the current environmental load of titanium dioxide is $1.5 \times 10^{-3} \mu \mathrm{g} \mathrm{m}^{-3}$ in air, $0.7 \mu \mathrm{g} \mathrm{L}^{-1}$ in water, and $0.4 \mu \mathrm{g}$ $\mathrm{kg}^{-1}$ in soil in Switzerland. The models predict that in the US, nanotitanium dioxide from manufactured sources is present at a concentration of $0.44 \mathrm{mg} \mathrm{kg}^{-1}$ in sediments downstream from sewage treatment plants and $0.35 \mathrm{mg} \mathrm{kg}^{-1}$ in sludgetreated soil. ${ }^{40,41}$

High concentrations of nano titanium doxide have demonstrated toxicity in erythrocyte studies. Doses of 25-800 $\mu \mathrm{g} \mathrm{mL}^{-1}$ of titanium dioxide particles (both nano and micro sizes) demonstrated an exponential relationship between dose and lysis of the cells. Nano-sized titanium dioxide particles were shown to have a significantly greater effect then micro titanium dioxide (cell lysis $\propto 0.025 \mathrm{e}^{0.5823 x}$ for nano-sized particles compared to cell lysis $\propto 0.0028 \mathrm{e}^{0.1425 x}$ for micro-sized particles, where $\mathrm{x}$ is the titanium dioxide concentration in $\left.\mu \mathrm{g} \mathrm{mL}^{-1}\right) .{ }^{42}$ This is in contrast to Karlsson et al's 
Table I Manufactured nanomaterial environmental concentrations and examples of toxicological thresholds

\begin{tabular}{|c|c|c|}
\hline Type of manufactured nanomaterial & Current m.e. or k.c. & Toxicological summary \\
\hline \multirow[t]{11}{*}{ Titanium dioxide $\left(\mathrm{TiO}_{2}\right)$} & m.e. Switzerland ${ }^{41}$ & Erythrocyte lysis ${ }^{42}$ \\
\hline & $1.5 \times 10^{-3} \mu g \mathrm{~m}^{-3}$ air & $25-800 \mathrm{mg} \mathrm{L}^{-1}$ \\
\hline & $0.7 \mu g \mathrm{~L}^{-1}$ water & \\
\hline & $0.4 \mu \mathrm{g} \mathrm{kg}{ }^{-1}$ soil & \\
\hline & m.e. United States ${ }^{40}$ & Epithelial cells DNA damage ${ }^{43}$ \\
\hline & $0.44 \mathrm{mg} \mathrm{kg}^{-1}$ sediments & $40-80 \mathrm{mg} \mathrm{L}^{-1}$ \\
\hline & $0.35 \mathrm{mg} \mathrm{kg}^{-1}$ sludge treated soil & \\
\hline & k.c. wastewater effluent & Planktonic membrane damage ${ }^{44}$ \\
\hline & California, Colorado, lowa, & $5.3 \mathrm{mg} \mathrm{L}^{-1}$ \\
\hline & Maryland, and New York ${ }^{48}$ & \\
\hline & $0.11 \mathrm{mg} \mathrm{L}^{-1}$ & \\
\hline \multirow[t]{9}{*}{ Carbon nanotubes } & m.e. aquatic sediments ${ }^{71}$ & Induction of cell death ${ }^{51}$ \\
\hline & $1.2-2,000 \mu g \mathrm{~kg}^{-1}$ & $2.5 \mathrm{mg} \mathrm{L}^{-1}$ \\
\hline & m.e. Switzerland ${ }^{41}$ & Dose-dependent body burden \\
\hline & $1.5 \times 10^{-3} \mu \mathrm{g} \mathrm{m}^{-3}$ air & Daphnia magna (no acute toxicity) ${ }^{52}$ \\
\hline & $5 \times 10^{-4} \mu \mathrm{g} \mathrm{L}^{-1}$ water & $0.04-0.4 \mathrm{mg} \mathrm{L}^{-1}$ \\
\hline & $\mathrm{I} \times 10^{-2} \mu \mathrm{g} \mathrm{kg}{ }^{-1}$ soil & \\
\hline & k.c. inside air homes with & Graphene is proving to be less \\
\hline & gas heating and cooking ${ }^{51}$ & cytotoxic than carbon nanotubes ${ }^{65}$ \\
\hline & $10^{4}-10^{5}$ particles $/ \mathrm{m}^{3}$ & \\
\hline \multirow[t]{19}{*}{ Quantum dots } & & 48 hour Daphnia magna $\mathrm{EC}_{50}$ values \\
\hline & & CdSe/ZnSe dots capped \\
\hline & & with mercaptpropionic acid 79 \\
\hline & & dark $>2500 \mu \mathrm{g} \mathrm{L^{-1 }}$ \\
\hline & & sunlight $384.5 \mu \mathrm{g} \mathrm{\textrm {L } ^ { - 1 }}$ \\
\hline & & 48 hour Daphnia magna $\mathrm{EC}_{50}$ values \\
\hline & & $\mathrm{CdSe} / \mathrm{ZnSe}$ dots capped with \\
\hline & & gum arabic/tri-n-octylphophine oxide ${ }^{79}$ \\
\hline & & dark $>1000 \mu \mathrm{g} \mathrm{L}^{-1}$ \\
\hline & & sunlight II.2 $\mu \mathrm{g} \mathrm{L}^{-1}$ \\
\hline & & Tail vein-injected CdSe/ZnS \\
\hline & & dots capped with polyethylene \\
\hline & & glycol persist in mouse \\
\hline & & lymph nodes for $>2$ years $^{82}$ \\
\hline & & Micro-motion assay determined \\
\hline & & mercaptopropionic acid coated \\
\hline & & $\mathrm{CdSe} / \mathrm{CdS} / \mathrm{ZnCdS} / \mathrm{ZnS}$ multi-shell \\
\hline & & quantum dots toxicity threshold91 \\
\hline & & $0.3 \mu \mathrm{M}$ \\
\hline \multirow[t]{9}{*}{ Silver nanoparticles } & m.e. Switzerland ${ }^{41}$ & Threshold of endocrine disruption \\
\hline & $4.4 \times 10^{-3} \mu g \mathrm{~m}^{-3}$ air & as determined by tail fin biopsy \\
\hline & $0.08 \mu \mathrm{g} \mathrm{L^{-1 }}$ water & assay derived from Rana catesbeiana \\
\hline & $0.1 \mu g \mathrm{~kg}^{-1}$ soil & tadpoles 98 \\
\hline & m.e. United States ${ }^{40}$ & $6 \mu \mathrm{g} \mathrm{L^{-1 }}$ \\
\hline & $21 \mu \mathrm{g} \mathrm{L}^{-1}$ sewage & Dose-dependent cytotoxicity, \\
\hline & treatment effluent & genotoxicity and cell cycle arrest \\
\hline & $1.6 \mu \mathrm{g} \mathrm{kg}{ }^{-1}$ sediments & human lung fibroblast and glioblastoma cells ${ }^{99}$ \\
\hline & $6.0 \mu \mathrm{g} \mathrm{kg}^{-1}$ sludge treated soil & $25-400 \mathrm{mg} \mathrm{L}^{-1}$ \\
\hline
\end{tabular}

Abbreviations: m.e., model estimated concentration; k.c., known concentration.

study on the toxicity of metal oxide nano and micro particles. Karlsson et al's study shows that in the human cell line A549 (alveolar type II-like epithelial cells) neither nano- nor micro-sized titanium dioxide show statistically higher cytotoxicity than control experiments at doses of $40-80 \mu \mathrm{g} \mathrm{mL}^{-1}$, micro-sized titanium dioxide causes more DNA damage then nano-sized titanium dioxide, but nano-sized titanium dioxide causes greater oxidative damage. ${ }^{43}$ These are two examples of contrasting results on the toxicity of nano-sized titanium dioxide. This is not surprising for two different cell lines. It just highlights the need of studying exposure routes and the most likely cells to be affected. 
Additional impetus for the need to develop new analytical methods comes from the modeling of the environmental concentrations of engineered nanomaterials done by Gottschalk et al. Their model for the concentration of titanium dioxide in sludge-treated soil in the US predicts a concentration of approximately $0.48 \mu \mathrm{g} \mathrm{g}^{-1}$ in $2012 .{ }^{40}$ This is well below the concentrations normally used in toxicity studies. In fact, it has been shown that at low concentrations $\left(0.01-1 \mu \mathrm{g} \mathrm{mL}^{-1}\right)$ titanium dioxide nanoparticles have no impact on the growth of marine phytoplankton. ${ }^{44}$ As suggested by Berube the benefits of emerging nanotechnology should not be stifled from reaching the consumer market by fear. The full body of research must be considered. As with all chemicals not all nanoparticles are the same, and we do ourselves a disservice if the properties of nanoparticles are overgeneralized. ${ }^{13}$ Environmental and exposure studies on titanium dioxide will not be effective for informing or enforcing policies until rapid, economical, and robust, analytical techniques are developed for measuring titanium dioxide size and concentration distributions in complex samples.

Some work on scalable models of titanium dioxide nanoparticle clearance from wastewater plants, toxicity to microbial communities at current environmental concentrations, and measurements of intake and release from actual wastewater plants has occurred in the past three years. Limbach et al, in 2008, published a study that used a model wastewater stream built according to the guidelines of the Organization for Economic Cooperation and Development. This model is accepted as a scalable model for studying the removal of toxins from wastewater streams. Cerium oxide particles with diameters of 20-50 nm were used as the model nanoparticles. Clearing sludge for the model wastewater plant was taken from the Zurich, Switzerland wastewater plant. Clearing sludge is a biological community of bacteria and protozoa that assist in the removal of pollutants in wastewater. It was found that the cerium oxide particles were not acutely toxic to the sludge in the $100-1000 \mathrm{ppm}$ range. After a stabilization period an inflow of 100 ppm cerium particles resulted in a $2-5$ ppm outflow of the nanoparticles. Nanoparticles are thus not fully removed from the effluent of the model wastewater treatment plant. Furthermore a high fraction of the cerium in the $2-5 \mathrm{ppm}$ outflow was in the smaller particle/aggregate size ranges. This outflow was stable despite the increasing cerium oxide concentration in the aeration (sludge) chamber. The study showed that peptone in the sludge contributed to enhanced stabilization of the nanoparticles at ionic strengths where they would usually agglomerate. ${ }^{45}$
Current wastewater treatment may thus be helping decrease, but not completely preventing the environmental release of nanoparticles into surface waters. In order to modify wastewater treatment plants for more efficient nanoparticle remediation we need to combine models of particle aggregation under the influence of ionic strength and $\mathrm{pH}$ with studies that look at the role natural compounds play in the stability of nanoparticles in the environment. ${ }^{46,47}$ This will help us in understanding the dominant factors in particle removal. Kiser et al studied the inflow and outflow of titanium dioxide particles at an actual wastewater reclamation facility in central Arizona. Analysis of digested samples by inductively coupled plasma optical emission spectroscopy (ICP-OES) was used to determine total titanium in inflow and outflow samples. A combination of centrifugation and scanning electron microscopy/electron dispersive X-ray microanalysis was used to characterize the morphology and size distribution of the titanium particles. It was found that raw sewage contained as much as $3000 \mu \mathrm{g} \mathrm{L}^{-1}$ titanium. After treatment the outflow contained between 10 and $100 \mu \mathrm{g} \mathrm{L}^{-1}$. While this looks promising, the titanium particles in the inflow were mostly larger than $0.7 \mu \mathrm{m}$ in diameter. Thus, total removal of titanium particles was $79 \% \pm 23 \%$, but if the size fraction that is less than $0.7 \mu \mathrm{m}$ is isolated and analyzed separately only $42 \% \pm 22 \%$ of this fraction is removed. ${ }^{48}$ Nano oxide material is currently being released into the environment as a higher percentage of inflow than micron-sized particles of the same material.

The wastewater outflow of nano titanium dioxide at a wastewater treatment plant in Arizona is $0.11 \mathrm{mg} \mathrm{L}^{-1}$, which is consistent with effluent from wastewater treatment plants in California, Colorado, Iowa, Maryland, and New York. ${ }^{48}$ This is consistent with Gottschalk's model predicting $0.016 \mathrm{mg} \mathrm{L}^{-1}$ concentration of titanium dioxide in watersheds downstream of wastewater treatment facilities in Switzerland. ${ }^{41}$ While most studies that demonstrate titanium dioxide toxicity demonstrate this toxicity at well above $0.016 \mathrm{mg} \mathrm{L}^{-1}$ or even above $0.11 \mathrm{mg} \mathrm{L}^{-1}$, a recent study shows significant cell membrane damage to planktonic free living cells after exposure for 24 hours to $5.3 \mathrm{mg} \mathrm{L}^{-1}$ titanium dioxide. Titanium engineered nanoparticles are the vanguard of what will be multiple types of engineered inorganic nanoparticles used for consumer goods and manufacturing. The toxicity of titanium dioxide nanoparticles is still open to debate. Analysis of samples by electron microscopy is time consuming and labor intensive. ICP-OES can provide quantification but not size characterization. Regardless of the toxicity, developing tools for the rapid identification, characterization, and quantification of titanium dioxide in air, water, and soil samples will 
help us understand the probable environmental distribution of emerging inorganic nanoparticles. Streamlined protocols that use a combination of techniques or techniques developed to take advantage of the unique properties of nanoparticles themselves are required. According to a recent review in the Journal of Analytical Chemistry, field flow fractionation (FFF) is poised to be the key tool in nanoparticle identification, characterization, and quantification. ${ }^{49}$

\section{Carbon nanotubes and graphene-based nanostructures}

Carbon nanotubes are molecular-scale tubes of graphitic carbon with many unique qualities, such as high surface area, high electrical conductivity, good chemical stability, and high mechanical strength. ${ }^{50}$ Because of these properties, carbon nanotubes have many potential applications, such as improved films and coatings, stronger and lighter materials, and applications in electronics. Carbon nanotubes already appear as a component of cosmetics, paints, filters, and reinforced plastics. ${ }^{3}$ Thus, carbon nanotubes are already part of the consumer waste stream. Multiple studies have shown that these engineered nanoparticles can have a detrimental effect on biological organisms. Many of these studies have been done on isolated cell lines, simple organisms, or small mammals. While these are useful as a preliminary assessment of toxicity, it is not straightforward to extrapolate the potential toxicity to the whole human organism.

Carbon nanotubes have been shown to have a similar toxicity to chrysotile asbestos in the murine lung macrophage cell line. Chrysotile asbestos is the mineral form of asbestos that is the least toxic and least likely to induce mesothelioma. In toxicology studies it is often chosen for comparison with carbon nanotubes because of its microstructural similarity to multi-wall carbon nanotubes and the wealth of toxicology data on it. Induction of cellular death for single-wall carbon nanotubes, multi-wall carbon nanotubes, and the asbestos control all begin at a concentration of $2.5 \mu \mathrm{g} \mathrm{mL}^{-1} .{ }^{51}$ In the Daphnia magna model organism, C14 labeled multi-wall carbon nanotubes were shown to accumulate in the organism's gut in an aquatic-only experimental environment. These accumulated carbon nanotubes did not fully clear even after changing the media and feeding the Daphnia with algae. This demonstrates the potential for carbon nanotube bioaccumulation in lower organisms resulting in a route for wider biodistribution. While no acute toxicity was found, a dose dependent body burden in Daphnia magna was shown for concentrations of nanotubes ranging from $0.04-0.4 \mu \mathrm{g} \mathrm{mL}^{-1} .52$ The cytotoxicity of nanotubes is not decreased upon aging in pure water for as many as 7 years. Conversely, exposure to natural organic matter or saline solution significantly decreases the toxicity of single-wall carbon nanotubes to human epithelial cells. This is probably due to blocking of the reactive groups on the surface of the nanotubes or facilitated aggregation of the nanotubes. ${ }^{53}$

These are just a few examples of carbon nanotube toxicity studies. Clearly, the toxicity of the nanotubes will be dependent on the specific nanotube chemistry, the exposure matrix (air, water, or soil), the interaction of the nanotubes with other compounds in the exposure matrix, and the organism. Additionally, interest in the impact of industrial production of designed carbon nanotubes will need to take into account natural and anthropogenic sources. How the current use of manufactured carbon nanotubes in commercial products has increased potential exposure must take into account the existing background of unintentionally produced carbon nanotubes. Transmission electron microscope (TEM) analysis has proven invaluable to the characterization and quantification of carbon nanotubes in air and simple matrices.

Graphene, the parent structure of nanotubes, is a two -dimensional network of $\mathrm{sp}^{2}$ bonded carbon atoms. This sheet is a layer one atom thick ( $\mathrm{z}$ axis), and the dimensions in the $\mathrm{x}$ and $\mathrm{y}$ axis are orders of magnitude larger than the thickness. A carbon nanotube can be thought of as a rolled graphene sheet. Until 2004, graphene was considered to be a theoretical construct. In 2004 mechanical exfoliation (peeling off layers using adhesive tape) of highly-ordered pyrolytic graphite yielded the first reported graphene structures. ${ }^{54}$ The high surface area and large regions of chemically active edges on graphene are responsible for the enhanced performance of this carbon allotrope over carbon nanotubes in electrochemical sensing, quantum electronics, and energy storage applications. ${ }^{55-58}$ Graphene has also been demonstrated as superior to carbon nanotubes in the photothermal treatment of cancer. ${ }^{59}$ Graphene is stronger than steel, provides high mobility for either electrons or holes, has high thermal conductivity, is transparent from the UV to the visible region of the electromagnetic spectrum, and is easy to chemically modify. ${ }^{55,56,60}$ Before graphene appears in high volume in consumer goods, fabrication methods need to be optimized for high throughput and homogeneous material properties. Mechanical exfoliation cannot be scaled industrially to result in high throughput. With thermal deposition it is hard to achieve single atom thickness. Chemical methods result in graphene-like material that deviates from pure graphene behavior both 
physically and chemically due to residual functional groups (primarily oxygen) left incorporated into the final product. ${ }^{57,61}$

Antibacterial paper fabricated from reduced graphene oxide (a graphene-like material) and graphene oxide, successfully prevented the growth of Escherichia coli bacteria in solution as well as on macro surfaces, while showing only mild cytotoxicity to the mammalian A549 cell line. ${ }^{62,63}$ Graphene-based antibacterial surfaces show promise for biomedical applications and also demonstrate that we should study the potential biological and environmental impact of graphene before it becomes a high volume material in consumer goods.

Graphene oxide was introduced via intravenous injection into Kun Ming mice at a dosage of $1 \mathrm{mg} \mathrm{kg}^{-1}$ in order to test the toxicity of this graphene-like material. Although these low doses did not result in pathological changes, it was found that the graphene oxide preferentially deposited in the lungs and cleared slowly from this organ. At doses of $10 \mathrm{mg} \mathrm{kg}^{-1}$ the accumulation of and slow clearance of graphene oxide from the lungs resulted in a host of pathological changes. ${ }^{64}$ When the cytotoxicity of graphene and single-wall carbon nanotubes was compared in neural pheochromocytomaderived PC12 cells, it was found that both were cytotoxic. The mechanism of cytotoxicity was dependent on both the type of material and the physical shape of the material. Cells were exposed to concentrations of graphene and ranging from 0.01 to $100 \mu \mathrm{g} \mathrm{mL}^{-1}$. At concentrations equal to or greater than $1 \mu \mathrm{g} \mathrm{mL}^{-1}$, single-wall carbon nanotubes resulted in a greater depression of metabolic activity than graphene and greater lactate dehydrogenase (cell necrosis indicator) release at all concentrations tested. Exposure to graphene resulted in a concentration and time dependent generation of reactive oxygen species. ${ }^{65}$ In biological applications, the size, shape, and functionalization of graphene will all play a role in the toxicity. After a dose of $20 \mathrm{mg} \mathrm{kg}^{-1}$, nanographene sheets functionalized with polyethylene glycol were injected into mice; minimum toxicity was found after 3 months ${ }^{66}$ Methods for monitoring graphitic material in biological systems and the environment will need to be able to differentiate nanostructures based on structure, size, and shape in order for health risks to be assessed.

If carbon nanotubes or graphene materials are to present an environmental or biological risk, it will only be if the concentrations of material from sources of manufactured nanomaterials exceed those demonstrated to result in biological damage. There is evidence that carbon-based nanomaterials have been part of Earth's ecosystem for thousands of years and there are natural mechanisms for degradation of these nanomaterials. TEM analysis of a 10,000-year-old ice core sample conclusively shows that the preindustrial atmospheric particle load 10,000 years ago included carbon nanotubes and related carbonaceous nanocrystals. ${ }^{67}$ Gas cooking and power plant combustion utilizing methane/air, natural gas/air, and propane gas/air flames are proven sources of unintentional carbon nanotube production. While a more efficient flame produces less particulate combustion products, a greater proportion of these products are crystalline carbon nanostructures. ${ }^{68-70}$ In homes where gas heating and cooking are prominent, there tends to be one to two orders of magnitude greater load of carbon nanotubes in the inside air compared with outdoor samples. Approximately $10^{4}-10^{5}$ particles $/ \mathrm{m}^{3}$ multi-wall carbon nanotube particle number concentrations were found. ${ }^{51}$

It has been harder to quantify environmental concentration in aqueous and soil samples. A recent exposure model developed by Koelmans et al suggests that the concentration and toxicological impact of manufactured carbonbased nanoparticles will be negligible in comparison to natural nanoparticles. The weight ratio of manufactured carbon-based nanoparticles to black carbon nanoparticles (naturally occurring and unintentionally produced carbon nanostructures) ranges from $4 \times 10^{-4}$ to $2.4 \times 10^{-7}$ from the worst case scenario to the realistic scenarios in estuarine and fresh waters. ${ }^{71}$ Currently there are orders of magnitude more naturally occurring and unintentionally produced carbon nanostructures in the environment than there are manufactured carbon nanomaterials.

As intentionally produced carbon nanostructures start to play a role in consumer materials and medicine, concentrations in waste streams may be quantified by liquid chromatography and mass spectrometry. ${ }^{1,37} \mathrm{FFF}$ has the potential to be a key analytical tool here as well. ${ }^{49}$ These techniques have not been applied widely in the literature for environmental or biological quantification of carbon nanotubes of graphemelike structures. Currently there is an increasing need for the development of analytical methods and protocols to support environmental models, testing, and regulation of carbon nanotube and graphene toxicity.

Techniques based on or related to chromatography can be used for the separation of nanoparticles in samples. By attaching traditional analytical tools (such as ICP mass spectrometry) as detectors to size separation techniques, it is not only possible to quantify different nanoparticles in food, water, and soil, but also to characterize or elementally analyze them. The best known technique for size separation is 
size exclusion chromatography. Spectroscopic methods also can be used for nanoparticle analysis and characterization. Scattering techniques include light scattering methods, such as static and dynamic light scattering, or neutron scattering. ${ }^{1}$ Some promising proof of principle publications include a method to separate the nanoparticle carbon $_{60}$ fullerene from water containing salts and organic matter and subsequent quantification of the concentrations using liquid chromatography coupled with mass spectrometry, ${ }^{72}$ and two-photon excitation microscopy to directly visualize carbon nanotubes, titanium dioxide, and cerium dioxide in plant samples. ${ }^{73}$

\section{Quantum dots}

Semiconductor quantum dots are nanoparticles that are important for possible therapeutic and diagnostic medical applications. Quantum dots are nano semiconductor crystals with tunable electrical and optical properties. The most common quantum dots are currently CdSe and CdTe cores with $\mathrm{CdS}$ or $\mathrm{ZnS}$ shells decorated with organic ligands to modify their solubility characteristics. In the nano size domain the electrical and spectral characteristics of these semiconductors are size tunable. The special characteristics of quantum dots that make them promising for medical applications include targeted drug delivery, cancer detection, and image guided surgery. ${ }^{74}$ Furthermore they have the potential for widespread application for economical and efficient solar cell production. ${ }^{75}$ While quantum dots are not currently widely used in medicine, medical imaging, or solar cell production, the technology is poised for rapid growth.

Monitoring of the environmental and in vivo concentrations of quantum dots will become an important part of the assessment of the risks and rewards of both the energy and medical applications of this technology. Recent studies have shown that even hydrophobic quantum dots are mobile in both aquatic and porous media. When a solution of CdSe quantum dots capped with hydrophobic ligands dissolved in hexane comes into contact with deionized water, minimal phase transfer occurs. This could lead one to believe that quantum dots would have limited mobility in the aquatic environment. This assumption would be wrong as natural organic matter (ie, fulvic and humic acids) plays a large role in the mobility or inorganic material in the aqueous environment. At a $\mathrm{pH}$ of 3 , in the presence of $20 \mathrm{ppm}$ fulvic acid, $100 \%$ of the quantum dots originally in the hexane solution (1:1 mixture of aqueous fulvic acid and 1.0-10 $\mu \mathrm{M}$ CdSe quantum dot suspension) transferred to the aqueous layer. A similar result was found with humic acid (46\% transfer in 24 hours).
Both $\mathrm{pH}$ and ionic strength of the aqueous solution play a role in the natural organic matter mediated phase transfer of quantum dots from hexane into the aqueous solution. The important point is that quantum dots and other inorganic nanoparticles will be mobile in the aquatic environment. ${ }^{76}$ The efficiency of the deposition of these mobilized particles in waste water settling tanks will also be a function of soil and water conditions. ${ }^{77}$ The presence of divalent and trivalent ions assists in aggregating quantum dots and facilitating their settling out of a water column. Alum can result (capping material dependent) in a 95\% removal efficiency of CdTe quantum dots from pure water. Tap water containing $\mathrm{Ca}^{2+}$ and $\mathrm{Mg}^{2+}$ results in $70 \%$ sedimentation efficiency. The addition of alum increases the sedimentation of the CdTe quantum dots from tap water. ${ }^{78}$

Toxicological studies suggest that we should be concerned about the transport and fate of semiconductor quantum dots in the environment and in vivo (if used for medical applications). The constituent ions $\mathrm{Cd}^{2+}, \mathrm{Se}^{2-}, \mathrm{Te}^{2-}$ of $\mathrm{CdSe}$ and $\mathrm{CdTe}$ core quantum dots already have known toxicity. In many cases the toxicity of semiconductor quantum dots is directly related to the stability (rate of leaching of $\mathrm{Cd}^{2+}, \mathrm{Se}^{2-}, \mathrm{Te}^{2-}$ ) of the constituent ions from the capped construct. Daphnia magna are common indicator species for water quality. This species has been applied to the study of semiconductor toxicology. In terms of acute toxicity of CdSe core ZnSe shell particles, it has been shown that the coating plays a large role in acute toxicity. A very stable coating results in a stable suspension of quantum dots in the water column. This longer suspension will result in greater ingestion of quantum dots by aquatic organisms. Conversely, quantum dots with a less stable coating will aggregate and precipitate out of the water column faster. This results in less ingestion of particles but a higher solution concentration of $\mathrm{Cd}^{2+}$, due to quantum dot degradation. ${ }^{79}$

Light exposure plays a role in quantum dot and $\mathrm{Cd}^{2+}$ toxicity. In terms of quantum dots, light exposure increases toxicity due to the generation of reactive oxygen species and photodegradation of the quantum dots. The photodegradation results in increased $\mathrm{Cd}^{2+}$ toxicity. The $\mathrm{EC}_{50}$ (median effect concentration for acute toxicity) values for Daphnia magna exposure to mercaptopropionic acid coated $\mathrm{CdSe} /$ $\mathrm{ZnSe}$ quantum dots (a strong covalent coating) in the dark were $>2500 \mu \mathrm{g} \mathrm{L}^{-1} \mathrm{Cd}$ and in sunlight $384.5 \mu \mathrm{g} \mathrm{L}^{-1}$ for a 48-hour time period. For gum arabic/tri-n-octylphosphine oxide coated $\mathrm{CdSe} / \mathrm{ZnSequantum}$ dots (a weakly interacting quantum dot coating) tested over the same time period, the $\mathrm{EC}_{50}$ values were $>1000 \mu \mathrm{g} \mathrm{L}^{-1}$ in the dark and $11.2 \mu \mathrm{g} \mathrm{L}^{-1}$ 
in sunlight. These data can be compared to the data on $\mathrm{CdCl}_{2}$ dissolved in the solution. $\mathrm{EC}_{50}$ values for the salt of $49.7 \mu \mathrm{g}$ $\mathrm{L}^{-1} \mathrm{Cd}$ in the dark and $1.9 \mu \mathrm{g} \mathrm{L}{ }^{-1}$ in sunlight. ${ }^{79}$ Fluorescence microscopy and ICP mass spectrometry studies have shown that when quantum dots are not at acutely toxic levels, they will bioaccumulate in Daphnia magna and they do not clear completely even after the organisms have been in quantum dot-free media for 48 hours. The total accumulation is dependent on the coating, but occurs regardless of the coating. Further concentration is thus possible in higher organisms feeding on contaminated filter feeders like Daphnia magna directly contaminated with quantum dots or feeding on quantum dot-contaminated bacteria. ${ }^{80,81}$

In vivo studies in mice show that quantum dots can persist in mice for at least 2 years. Tail vein injected CdSe core $\mathrm{ZnS}$ capped polyethylene glycol coated quantum dots rapidly cleared from circulation into the reticuloendothelial system. Quantum dots can persist in the liver for 2-5 days, bone marrow 3-6 months, and lymph nodes up to 2 years. ${ }^{82}$ It will be important to understand the characteristics determining persistence of quantum dots in vivo when they are applied to medical applications.

The potential advances in biomedical imaging resulting from quantum dots have led to a number of publications exploring methods for optimizing their biocompatibility. Surface ligands that increase water solubility and decrease protein adsorption are seen as desirable for increased blood stream circulation and increased biocompatibility. A systematic exploration of amphiphilicpolymer micelles for the encapsulation of quantum dots with tri-n-octyphosphineoxide surface ligands reported on the optimization of hydrophobic chain length, percentage of hydrophobic chains per ligand, and ratio of polymer to quantum dots (weight ratios) to determine the best amphiphilic polymer construct for promoting water solubility of quantum dots and minimizing protein adsorption. The hydrophobic chain length and percentage of hydrophobic chains have a direct impact on how well the polymer encapsulates and protects the quantum dot from an aqueous solution. The number of ligands per quantum dot will play a role in the long term stability of the quantum dots. It was found that $40 \%$ modification of poly (acrylic acid) with dodecylamine or octadecylamine gave the best transfer of quantum dots into aqueous solution. The transfer efficiencies were not only correlated with carbon chain length but also with the steric interaction of the carbon chains on the amphiphilic polymer with the carbon chains of the quantum dot ligands. Protein binding to the encapsulated quantum dots depended on the protein studied as both surface modification and the physical characteristics of the protein will play a role. This study did not make any specific generalizations about the best polymer constructs to prevent protein binding, but it was hypothesized that PEGylation would reduce the nonspecific binding of protein. ${ }^{83}$

Encapsulation of CdSe/ZnS quantum dots in micelles of amphiphilic polymers leads to water solubility and stability in the $\mathrm{pH}$ range 4-13 with a construct lifetime of several months. ${ }^{83}$ Even greater stability is required for the application of these quantum dots in biomedical applications. Cadmium is a heavy metal with known toxicity at low concentrations. Any leaching of cadmium from the biomedical device to the patient has the potential to cause harm. Improved quantum dot stability can be obtained by the direct interaction of ligands that promote water solubility and reduce protein binding with the quantum dot surface. Ligands with a poly(methacrylate) backbone and poly(ethylene glycol) chains that anchor to $\mathrm{CdSe} / \mathrm{ZnS}$ quantum dots through pendant thiol groups resulted in quantum dots that are stable in aqueous environments in the $\mathrm{pH}$ range 5-9. These quantum dot constructs were found to be transported across the cell membrane of human umbilical vein endothelial cells to be localized in either the cytosol or nucleus (depending on the chemistry of the ligands). Incubation for 48 hours in a solution containing $500 \mathrm{~nm}$ quantum dots did not affect the viability or the growth of the endothelial cells. ${ }^{84}$

The stability of polymer ligands is improved with the use of a multidentate imidazole binding motif instead of thiols for interaction with the quantum dot surface. Reversible additionfragmentation chain transfer-mediated polymerization was used to synthesize imidazole, poly(ethylene glycol), and primary amine or biotin copolymers for utilization as quantum dot ligands. These quantum dot constructs demonstrated 2 month stability in aqueous solutions, were stable in $\mathrm{pH}$ range 5-10.5, and had negligible nonspecific protein binding when incubated with HeLa cells or blood serum. In live animal studies these constructs cleared from mouse vasculature in 3 hours and in 6 hours had primarily extravasated into the mouse breast tumor tissue. ${ }^{85}$ While new ligands for quantum dots have improved water solubility and stability and are proven to be nontoxic in short term studies, there continues to be worry about long-term exposure. The constructs will not be stable indefinitely and study needs to be done on cell/animal clearance of the particles. It has been shown that quantum dots can persist in mice for at least 2 years and as the quantum dot constructs are degraded there will be chronic exposure of the organism to low doses of cadmium. ${ }^{82}$ Concerns over the fate of heavy metals in semiconductor 
quantum dots used for biomedical applications have led to research on biocompatible nanomaterials with physical properties analogous to semiconductor quantum dots. Carbon dots and silicon quantum dots are showing promise as entities that will realize the advantages of semiconductor quantum dots without the toxicity. ${ }^{86,87}$

The key technologies for quantum dot characterization and quantification in the studies mentioned above are fluorescence spectroscopy, fluorescence microscopy, and ICP-OES. A combination of fluorescence analysis and ICPOES is required for characterization and quantification or localization and quantification. TEM also continues to play a large role in nanoparticle identification, characterization, and quantification. ${ }^{88}$ In one example, TEM analysis has already demonstrated that inorganic nanosized contamination can be found in bread and biscuits. ${ }^{89}$ The time required for sample preparation is prohibitive for the application of TEM to the large sample throughput that will be necessary for the environmental and medical monitoring of quantum dot fate in environmental and medical applications. Two developing technologies may hold the key to rapid characterization and quantification of quantum dots. For determination of and characterization of quantum dots in environmental and biological samples hyphenated forms of FFF shows promise. ${ }^{49}$ For toxicity, electric cell-substrate impedance sensing (ECIS) can provide a rapid assay for threshold levels of the impact of newly developed nanomaterials on cell metabolism. ${ }^{90}$ In ECIS an adherent cell line is allowed to attach to an electrode. In the toxicology assay described by Janshoff et al, ${ }^{91}$ the impedance of the cell covered electrode is measured at a fixed alternating current frequency. Fluctuation in the impedance is due to fluctuations of cell shape. The fluctuation in adherent cell shape is known as micromotion. The rate of micromotion is correlated to cell metabolic activity and thus can serve as a measure of viability. Using in vitro assay it was determined that mercaptopropionic acid coated $\mathrm{CdSe} /$ $\mathrm{CdS} / \mathrm{ZnCdS} / \mathrm{ZnS}$ multi-shell quantum dots were toxic at a concentration of $0.3 \mu \mathrm{M}$. The same experiment performed using the established MTS assay showed toxicity at $2 \mu \mathrm{m} .{ }^{91}$ ECIS correlates to established methods but will prove to be a more sensitive measure of nanoparticle toxicity.

\section{Gold and silver}

Gold and silver nanoparticles are currently found in a wide variety of consumer products. They are used in automobile sensors, cosmetics, sugar monitors, and cancer treatments. ${ }^{6}$ Silver nanoparticles are used in antibacterial agents, textile engineering, water treatment, and silver-based consumer products. ${ }^{92}$ Silver nanoparticles are also utilized in a wide range of medical devices, one being the treatment of human immunodeficiency virus- $1 .{ }^{93}$ Silver nanoparticles are one of the most widely used engineered nanoparticles in consumer products. Textiles taking advantage of the antimicrobial, antifungal, and antiviral properties of nano silver have led to an increase of use in consumer products. ${ }^{3}$ Benn and Westerhoff ${ }^{94}$ studied the release of silver nanoparticles from commercially available antimicrobial socks utilizing nano silver. Tested socks contained between 0 and $1360 \mu \mathrm{g} \mathrm{g}^{-1}$ silver/g sock mass. Depending on the manufacturing process, the socks either continued to leach significant amounts of silver after four washes or had leached all of their silver after four washes. Ion selective electrode data was used in conjunction with ICP analysis of wash water to differentiate silver loss as colloidal silver compared to loss as ionized silver. The high surface area of the nanoparticles led to the conversion of a significant portion of the colloidal silver mass into ionic silver. Benchtop modeling of waste water treatment suggest that despite the increased environmental load of colloidal silver and ionized silver, current wastewater treatment plants will be able to handle the increased load of these contaminants (despite the antimicrobial effect on wastewater activated sludge) ${ }^{94}$

Nowack's exposure models predicts the concentration (2008, high emission scenario) of nano silver to be $4.4 \times 10^{-3} \mu \mathrm{g} \mathrm{M}^{-3}$ in air, $0.08 \mu \mathrm{g} \mathrm{L}^{-1}$ in water, and $0.1 \mu \mathrm{g} \mathrm{kg}^{-1}$ in soil in Switzerland. In the US, the sewage treatment effluent is predicted to be $21 \mu \mathrm{g} \mathrm{L} \mathrm{L}^{-1}$ (2008), with $6.0 \mu \mathrm{g}$ $\mathrm{kg}^{-1}$ nano silver in sludge-treated soil, and $1.6 \mu \mathrm{g} \mathrm{kg}^{-1}$ in sediments (2011). ${ }^{40,41}$ In agreement with Benn and Westerhoff's benchtop modeling, ${ }^{94}$ all of these concentrations are below the currently accepted toxicology threshold of nano silver.

Little is known about the current concentration of engineered gold nanoparticles in the environment. It is known that natural organic matter and humic substances can increase the stability of gold nanoparticles in aqueous solution. ${ }^{95}$ Gold nanoparticles can accumulate and be magnified by bioaccumulation through the food chain. ${ }^{96}$ The low background concentration of gold and gold nanoparticles in the environment will make the determination of the fate of engineered nanoparticles in the environment and in biological models useful in understanding the potential fate of other nanoparticles. The low toxicity of gold nanoparticles suggests that there is low potential for adverse environmental or biological impact from these particles. ${ }^{90,97}$ 
While silver is currently not considered to be a significant human health risk, recent studies indicate that nanosilver has a unique toxicology profile compared to silver ion or micrometer silver. At a concentrations of $6 \mu \mathrm{g} \mathrm{L}^{-1}$, nanosilver resulted in triiodothyronine dependent transcriptase disruption characteristic of endocrine disruption in tail fin biopsy assay derived from Rana catesbeiana tadpoles, a response not seen upon exposure to silver ion or micrometer silver. ${ }^{98}$ At high concentrations $\left(25-400 \mu \mathrm{g} \mathrm{mL}^{-1}\right)$, well above those predicted in current waste streams, nanosilver has been shown to have a dose-dependent cytotoxicity, genotoxicity, and cell cycle arrest in human lung fibroblast cells and human glioblastoma cells. Nanosilver is found to localize in mitochondria, resulting in mitochondria damage. The net toxicity is function of the nanosilver size, shape, surface functionalized and the kinetics of oxidation and resultant loss of the silver ion. ${ }^{99}$ At $1000 \mathrm{mg} \mathrm{L}^{-1}$, nano silver does not affect the germination or root growth of Cucurbita pepo (zucchini) compared to bulk material. Nano silver does have an impact on biomass gains. At $500 \mathrm{mg} \mathrm{L}^{-1}$, biomass is reduced by $57 \%$ compared to bulk controls and transpiration volume is reduced by $78 \% .{ }^{100}$

Exposure to high levels of nanosilver can be toxic and the toxicity profile is different from that of ionic silver. Our level of concern should be based on current and projected environmental concentrations and biomedical loads of nanosilver. The current studies suggest that nanosilver is not currently a major concern for nanotoxicity. Regardless, nanosilver's economic value and wide distribution in consumer products make it a good candidate for regulation and monitoring. As with titanium dioxide nanoparticles and semiconductor quantum dots, currently a variety of techniques are required to characterize and quantify silver nanoparticles. Beyond examples of electron microscopy, these authors found little evidence of the common characterization techniques being applied to environmental screening of nanoparticles. Most were applied to characterization and quantification of silver nanoparticles in environmental and biological samples exposed to known concentration of nanosilver. The complexity and high volume of the eventual environmental samples that result from eventual regulation of the nanoparticle industry may well served by the rapidly developing technology of FFF and the related FFF-hyphenated methods. ${ }^{49}$

\section{Conclusion}

Though there is great promise for the future of nanotechnology, it is essential to understand that the properties of nanomaterials make up a 'two-edged sword'. The same ways that nanomaterials are hypothesized to be beneficial to medicine could also be ways in which nanomaterials are possibly detrimental to human health as well as the environment. The very dimensions of nanoparticles that result in multiple benefits for medical applications may cause these nanoparticles to selectively accumulate inside the body, which could result in tissue damage. Once inside the body, nanomaterials seem to have unlimited access to all tissues and organs, and though they can be successful in destroying tumors and other malignant growths within the body, it is not certain what happens to these particles afterwards. ${ }^{4}$ One particular nanoparticle, carbon nanotubes, which are long and thin, have been found to have many toxilogical similarities to the cancer-causing asbestos fibers, which cause lung damage. ${ }^{51}$ Another nanoparticle, titanium dioxide, which is commonly used in sunscreen, is known to wash out of products and enter waste streams, where it may harm aquatic life. ${ }^{39}$ These, as well as several other examples, encapsulate the issue of potential toxicity in nanotechnology, and though most branches of nanotechnology will pose no significant hazards to human health or the environment, it is necessary to have a thorough scientific assessment of the possible dangers before engineered nanoparticles become of major use in society.

A number of papers and articles can be found regarding the theory and establishment of nanoparticle toxicity. Nonetheless, the novelty and ambiguity of this topic has lead to the creation of an increasing number of commercial products containing nanoparticles (current number exceeds 1500) with minimal regulation from the FDA. Nanotechnology is developing and being commercialized more rapidly than its toxicity is being studied or regulated. ${ }^{3}$ The lack of a thorough understanding of the science of nanotechnology and how regulators should subdivide it prevents FDA from reasonably protecting public health. ${ }^{2,33,34}$ Because nanotechnology is a very new form of technology and some of the potential hazards are not the usual hazards considered when evaluating health effects, regulatory agencies have a hard time classifying nanomaterial, causing them to 'attach' nanotechnology to existing regulations, despite clear gaps. This allows some nanotechnology applications to slip through cracks, without being covered by any regulations. ${ }^{2}$ Another reason the many nanoingredients have been able to be in commercial products is because they are declared "Generally Recognized as Safe" (GRAS) - a classification given to foods and food additives that have a history of safe use. ${ }^{2,33,34}$ While the macro form of an ingredient may be considered GRAS, nano versions should not be assumed to follow suit because the smallness of 
these molecules cause them to be more toxic and potentially dangerous.

The lack of a complete understanding of the characteristics of nanotechnology and the possible toxicity of nanoparticles are not the only reasons for the deficiency of research monitoring the role of nanomaterials in the environment or in medical diagnostic. Little is known about how the new physicochemical properties that make engineered nanomaterials so attractive for use in consumer products interact at the nano/bio interface. Much debate is underway about how to proceed with nanomaterial toxicity testing, mainly regarding which toxicological end points to screen for, the depth of the screening effort, the balance of in vitro versus in vivo testing, the cost of the effort, and who should be responsible for screening and safety assessment of nanomaterials. As this is a very new, innovative technology, new analytical techniques will have to be developed that focus on the quantification of the physical, chemical, and toxicological properties that make nanomaterials unique. In other words we need to develop nanoproperty-quantifying sensors.

\section{Acknowledgments}

This work was financially supported by the Colorado College Dean's Advisory Committee and the Colorado College Venture Fund.

\section{Disclosure}

The authors report no conflicts of interest in this work.

\section{References}

1. Tiede K, Boxall AB, Tear SP, Lewis J, David H, Hassellov M. Detection and characterization of engineered nanoparticles in food and the environment. Food Addit Contam Part A Chem Anal Control Expo Risk Assess. 2008;25(7):795-821.

2. United States Environmental Protection Agency (EPA). 2007. Nanotechnology White Paper. Washington, DC: United States Environmental Protection Agency; 2007. Publication No: EPA 100/B-07/001.

3. Woodrow Wilson International Center for Scholars, Project on Emerging Nanotechnologies. Consumer products: an inventory of nano-technology based consumer products currently on the market. December 12, 2010. Available at: http://www.nanotechproject.org/inventories/consumer. Accessed March 5, 2011.

4. Grodzinski P. Cancer nanotech: breakthrough technologies for recognition and therapy of cancer. Symposium on Nanotechnology and Occupational Health; 2005 Oct 3-6; Minneapolis, MN.

5. Giljohann DA, Seferos DS, Daniel WL, Massich MD, Patel PC, Mirkin CA. Gold nanoparticles for biology and medicine. Angew Chem Int Ed Engl. 2010;49(19):3280-3294.

6. Chen PC, Mwakwari SC, Oyelere AK. Gold nanoparticles: from nanomedicine to nanosensing. Nanotechnol Sci Appl. 2008;1:45-66.

7. Cormode DP, Skajaa T, Fayad ZA, Mulder WJ. Nanotechnology in medical imaging probe design and applications. Arterioscler Thromb Vasc Biol. 2009;29(7):992-1000.
8. Portney NG, Ozkan M. Nano-oncology: drug delivery, imaging, and sensing. Anal Bioanal Chem. 2006;384(3):620-630.

9. Pradeep T, Anshup. Noble metal nanoparticles for water purification: a critical review. Thin Solid Films. 2009;517(24):6441-6478.

10. Sagawa T, Yoshikawa S, Imahori H. One-dimensional nanostructured semiconducting materials for organic photovoltaics. J Phys Chem Lett. 2010;1(7):1020-1025.

11. Li Y, Somorjai GA. Nanoscale advances in catalysis and energy applications. Nano Lett. 2010;10(7):2289-2295.

12. Hu X, Li G, Yu JC. Design, fabrication, and modification of nanostructured semiconductor materials for environmental and energy applications. Langmuir. 2009;26(5):3031-3039.

13. Berube DM. Rhetorical gamesmanship in the nano debates over sunscreens and nanoparticles. J Nanopart Res. 2008;10(Supp1 1): 23-37.

14. Kafizas A, Kellici S, Darr JA, Parkin IP. Titanium dioxide and composite metal/metal oxide titania thin films on glass: a comparative study of photocatalytic activity. J Photochem Photobiol A. 2009;204(2-3): 183-190.

15. Muller S. Magnetic fluid hyperthermia therapy for malignant brain tumors-an ethical discussion. Nanomedicine. 2009;5(4):387-393.

16. Gao JH, Gu HW, Xu B. Multifunctional magnetic nanoparticles: design, synthesis, and biomedical applications. Acc Chem Res. 2009; 42(8):1097-1107.

17. Jones EF, He J, Vanbrocklin HF, Franc BL, Seo Y. Nanoprobes for medical diagnosis: current status of nanotechnology in molecular imaging. Curr Nanosci. 2008;4(1):17-29.

18. Majewski P, Thierry B. Functionalized magnetite nanoparticles synthesis, properties, and bio-applications. Crit Rev Solid State. 2007; 32(3-4):203-215.

19. Couleaud P, Morosini V, Frochot C, Richeter S, Raehm L, Durand JO. Silica-based nanoparticles for photodynamic therapy applications. Nanoscale. 2010;2(7):1083-1095.

20. McInnes SJ, Voelckert NH. Silicon-polymer hybrid materials for drug delivery. Future Med Chem. 2009;1(6):1051-1074.

21. Knopp D, Tang D, Niessner R. Bioanalytical applications of biomolecule-functionalized nanometer-sized doped silica particles. Anal Chim Acta. 2009;647(1):14-30.

22. Somorjai GA, Frei H, Park JY. Advancing the frontiers in nanocatalysis, biointerfaces, and renewable energy conversion by innovations of surface techniques. J Am Chem Soc. 2009;131(46):16589-16605.

23. Walling MA, Novak JA, Shepard JR. Quantum dots for live cell and in vivo imaging. Int J Mol Sci. 2009;10(2):441-491.

24. Kamat PV. Quantum dot solar cells. Semiconductor nanocrystals as light harvesters. J Phys Chem C. 2008;112(48):18737-18753.

25. Osterloh FE. Inorganic materials as catalysts for photochemical splitting of water. Chem Mater. 2008;20(1):35-54.

26. Bhaskar S, Tian FR, Stoeger T, et al. Multifunctional nanocarriers for diagnostics, drug delivery and targeted treatment across blood-brain barrier: perspectives on tracking and neuroimaging. Part Fibre Toxicol. 2010;7:3.

27. Hilder TA, Hill JM. Modeling the loading and unloading of drugs into nanotubes. Small. 2009;5(3):300-308.

28. Fernandes C, Soni U, Patravale V. Nano-interventions for neurodegenerative disorders. Pharmacol Res. 2010;62(2):166-178.

29. Cevc G, Vierl U. Nanotechnology and the transdermal route: a state of the art review and critical appraisal. J Control Release. 2010;141(3): $277-299$.

30. Sagalowicz L, Leser ME. Delivery systems for liquid food products. Curr Opin Colloid In. 2010;15(1-2):61-72.

31. Puri A, Loomis K, Smith B, et al. Lipid-based nanoparticles as pharmaceutical drug carriers: from concepts to clinic. Crit Rev Ther Drug Carrier Syst. 2009;26(6):523-580.

32. Popov AM, Lozovik YE, Fiorito S, Yahia L. Biocompatibility and applications of carbon nanotubes in medical nano robots. Int $J$ Nanomedicine. 2007;2(3):361-372. 
33. Beaudrie C; The Chemical Heritage Foundation. Emerging nanotechnologies and life-cycle regulation: an investigation of federal regulatory oversight from nanomaterial production to end of life. 2010. Available at: http://www.chemheritage.org/Downloads/Publications/ White-Papers/Studies-in-Sustainability_Beaudrie.pdf.Accessed March 5, 2011.

34. Lamprou A; The Chemical Heritage Foundation. Nanotechnology regulation: policies proposed by three organizations for the reform of the toxic substances control act. 2010. Available at: http://www chemheritage.org/Downloads/Publications/White-Papers/Studiesin-Sustainability_Lamprou.pdf. Accessed March 5, 2011.

35. Sandoval B. Perspectives on FDA's regulation of nanotechnology: emerging challenges and potential solutions. Compr Rev Food Sci Food Safety. 2009;8(4):375-393.

36. Rivera Gil P, Oberdorster G, Elder A, Puntes V, Parak WJ. Correlating physico-chemical with toxicological properties of nanoparticles: the present and the future. ACS Nano. 2010;4(10):5527-5531.

37. Tiede K, Hassellov M, Breitbarth E, Chaudhry Q, Boxall AB. Considerations for environmental fate and ecotoxicity testing to support environmental risk assessments for engineered nanoparticles. J Chromatogr A. 2009;1216(3):503-509.

38. Bowers J, Monosson E; The Encyclopedia of Earth. Nano Titanium Dioxide. April 23, 2010. Available at: http://www.eoearth.org/article/ Nano_Titanium_Dioxide. Accessed August 16, 2010.

39. International Center for Technology Assessment. Citizen petition to the United States Food and Drug Administration: petition requesting FDA amend its regulations for products composed of engineered nanoparticles generally and sunscreen drug products composed of engineered nanoparticles specifically. 2006. Available from: http:/www.icta org/doc/Nano\%20FDA\%20petition\%20final.pdf. Accessed May 26, 2011.

40. Gottschalk F, Sonderer T, Scholz RW, Nowack B. Modeled environmental concentrations of engineered nanomaterials ( $\mathrm{TiO}(2), \mathrm{ZnO}, \mathrm{Ag}$, CNT, Fullerenes) for different regions. Environ Sci Technol. 2009; 43(24):9216-9222.

41. Mueller NC, Nowack B. Exposure modeling of engineered nanoparticles in the environment. Environ Sci Technol. 2008;42(12):4447-4453.

42. Li SQ, Zhu RR, Zhu H, et al. Nanotoxicity of TiO2 nanoparticles to erythrocyte in vitro. Food Chem Toxicol. 2008;46(12): 3626-3631.

43. Karlsson HL, Gustafsson J, Cronholm P, Moller L. Size-dependent toxicity of metal oxide particles-a comparison between nano- and micrometer size. Toxicol Lett. 2009;188(2):112-118.

44. Miller RJ, Lenihan HS, Muller EB, Tseng N, Hanna SK, Keller AA. Impacts of metal oxide nanoparticles on marine phytoplankton. Environ Sci Technol. 2010;44(19):7329-7334.

45. Limbach LK, Bereiter R, Muller E, Krebs R, Galli R, Stark WJ. Removal of oxide nanoparticles in a model wastewater treatment plant: influence of agglomeration and surfactants on clearing efficiency. Environ Sci Technol. 2008;42(15):5828-5833.

46. French RA, Jacobson AR, Kim B, Isley SL, Penn RL, Baveye PC. Influence of ionic strength, $\mathrm{pH}$, and cation valence on aggregation kinetics of titanium dioxide nanoparticles. Environ Sci Technol. 2009;43(5): 1354-1359.

47. Domingos RF, Tufenkji N, Wilkinson KI. Aggregation of titanium dioxide nanoparticles: role of a fulvic acid. Environ Sci Technol. 2009; 43(5):1282-1286.

48. Kiser MA, Westerhoff P, Benn T, Wang Y, Perez-Rivera J, Hristovski K. Titanium nanomaterial removal and release from wastewater treatment plants. Environ Sci Technol. 2009;43(17):6757-6763.

49. Williams SK, Runyon JR, Ashames AA. Field-flow fractionation: addressing the nano challenge. Anal Chem. 2011;83(3):634-642.

50. Chen CC, Chen CF, Chen CM, Chuang FT. Modification of multi-walled carbon nanotubes by microwave digestion method as electrocatalyst supports for direct methanol fuel cell applications. Electrochem Commun. 2007;9(1):159-163.
51. Murr LE, Garza KM, Soto KF, et al. Cytotoxicity assessment of some carbon nanotubes and related carbon nanoparticle aggregates and the implications for anthropogenic carbon nanotube aggregates in the environment. Int $J$ Environ Res Public Health. 2005;2(1): 31-42.

52. Petersen EJ, Akkanen J, Kukkonen JV, Weber WJ Jr. Biological uptake and depuration of carbon nanotubes by Daphnia magna. Environ Sci Technol. 2009;43(8):2969-2975.

53. Panessa-Warren BJ, Maye MM, Warren JB, Crosson KM. Single walled carbon nanotube reactivity and cytotoxicity following extended aqueous exposure. Environ Pollut. 2009;157(4):1140-1151.

54. Novoselov KS, Geim AK, Morozov SV, et al. Electric field effect in atomically thin carbon films. Science. 2004;306(5696):666-669.

55. Dragoman M, Dragoman D. Graphene-based quantum electronics. Prog Quant Electron. 2009;33(6):165-214.

56. Pumera M. Graphene-based nanomaterials and their electrochemistry. Chem Soc Rev. 2010;39(11):4146-4157.

57. Bai H, Li C, Shi G. Functional composite materials based on chemically converted graphene. Adv Mater. 2011;23(9):1089-1115.

58. Pumera M. Graphene-based nanomaterials for energy storage. Energy Environ Sci. 2011;4(3):668-674.

59. Markovic ZM, Harhaji-Trajkovic LM, Todorovic-Markovic BM, et al. In vitro comparison of the photothermal anticancer activity of graphene nanoparticles and carbon nanotubes. Biomaterials. 2011; 32(4):1121-1129.

60. Chen YP, Yu Q. Nanomaterials: graphene rolls off the press. Nat Nanotechnol. 2010;5(8):559-560.

61. Yang WR, Ratinac KR, Ringer SP, Thordarson P, Gooding JJ, Braet F. Carbon nanomaterials in biosensors: should you use nanotubes or graphene? Angew Chem Int Ed Engl. 2010;49(12):2114-2138.

62. Hu W, Peng C, Luo W, et al. Graphene-based antibacterial paper. ACS Nano. 2010;4(7):4317-4323.

63. Chang Y, Yang ST, Liu JH, et al. In vitro toxicity evaluation of graphene oxide on A549 cells. Toxicol Lett. 2011;200(3):201-210.

64. Zhang X, Yin J, Peng C, et al. Distribution and biocompatibility studies of graphene oxide in mice after intravenous administration. Carbon. 2011;49(3):986-995.

65. Zhang Y, Ali SF, Dervishi E, et al. Cytotoxicity effects of graphene and single-wall carbon nanotubes in neural phaeochromocytoma-derived PC12 cells. ACS Nano. 2010;4(6):3181-3186.

66. Yang K, Wan J, Zhang S, Zhang Y, Lee ST, Liu Z. In vivo pharmacokinetics, long-term biodistribution, and toxicology of PEGylated graphene in mice. ACS Nano. 2011;5(1):516-522.

67. Esquivel EV, Murr LE. A TEM analysis of nanoparticulates in a polar ice core. Mater Charact. 2004;52(1):15-25.

68. Bang JJ, Murr LE, Esquivel EV. Collection and characterization of airborne nanoparticulates. Mater Charact. 2004;52(1):1-14.

69. Murr LE, Soto KF, Esquivel EV, et al. Carbon nanotubes and other fullerene-related nanocrystals in the environment: a TEM study. JOM-J Min Met Mat S. 2004;56(6):28-31.

70. Murr LE, Bang JJ, Esquivel EV, Guerrero PA, Lopez DA. Carbon nanotubes, nanocrystal forms, and complex nanoparticle aggregates in common fuel-gas combustion sources and the ambient air. J Nanopart Res. 2004;6(2):241-251.

71. Koelmans AA, Nowack B, Wiesner MR. Comparison of manufactured and black carbon nanoparticle concentrations in aquatic sediments. Environ Pollut. 2009;157(4):1110-1116.

72. Chen Z, Westerhoff P, Herckes P. Quantification of C60 fullerene concentrations in water. Environ Toxicol Chem. 2008;27(9): $1852-1859$

73. Wild E, Jones KC. Novel method for the direct visualization of in vivo nanomaterials and chemical interactions in plants. Environ Sci Technol. 2009;43(14):5290-5294.

74. Rzigalinski BA, Strobl JS. Cadmium-containing nanoparticles: perspectives on pharmacology and toxicology of quantum dots. Toxicol Appl Pharmacol. 2009;238(3):280-288. 
75. Sengul $\mathrm{H}$, Theis TL. An environmental impact assessment of quantum dot photovoltaics (QDPV) from raw material acquisition through use. J Clean Prod. 2011;19(1):21-31.

76. Navarro DA, Watson DF, Aga DS, Banerjee S. Natural organic mattermediated phase transfer of quantum dots in the aquatic environment. Environ Sci Technol. 2009;43(3):677-682.

77. Torkzaban S, Kim Y, Mulvihill M, Wan J, Tokunaga TK. Transport and deposition of functionalized CdTe nanoparticles in saturated porous media. J Contam Hydrol. 2010;118(3-4):208-217.

78. Zhang Y, Chen Y, Westerhoff P, Crittenden JC. Stability and removal of water soluble CdTe quantum dots in water. Environ Sci Technol. 2007;42(1):321-325.

79. Lee J, Ji K, Kim J, et al. Acute toxicity of two CdSe/ZnSe quantum dots with different surface coating in Daphnia magna under various light conditions. Environ Toxicol. 2009;25(6):593-600.

80. Lewinski NA, Zhu H, Jo HJ, et al. Quantification of water solubilized $\mathrm{CdSe} / \mathrm{ZnS}$ quantum dots in Daphnia magna. Environ Sci Technol. 2010;44(5):1841-1846.

81. Werlin R, Priester JH, Mielke RE, et al. Biomagnification of cadmium selenide quantum dots in a simple experimental microbial food chain. Nat Nanotechnol. 2011;6(1):65-71.

82. Fitzpatrick JA, Andreko SK, Ernst LA, Waggoner AS, Ballou B, Bruchez MP. Long-term persistence and spectral blue shifting of quantum dots in vivo. Nano Lett. 2009;9(7):2736-2741.

83. Anderson RE, Chan WC. Systematic investigation of preparing biocompatible, single, and small $\mathrm{ZnS}$-capped CdSe quantum dots with amphiphilic polymers. ACS Nano. 2008;2(7):1341-1352.

84. Yildiz I, McCaughan B, Cruickshank SF, Callan JF, Raymo FM. Biocompatible CdSe-ZnS core-shell quantum dots coated with hydrophilic polythiols. Langmuir. 2009;25(12):7090-7096.

85. Liu W, Greytak AB, Lee J, et al. Compact biocompatible quantum dots via RAFT-mediated synthesis of imidazole-based random copolymer ligand. J Am Chem Soc. 2009;132(2):472-483.

86. Yang ST, Wang X, Wang H, et al. Carbon dots as nontoxic and highperformance fluorescence imaging agents. J Phys Chem C Nanomater Interfaces. 2009;113(42):18110-18114.

87. Erogbogbo F, Yong KT, Hu R, et al. Biocompatible magnetofluorescent probes: luminescent silicon quantum dots coupled with superparamagnetic iron(III) oxide. ACS Nano. 2010;4(9):5131-5138.

88. Leppard GG. Nanoparticles in the environment as revealed by transmission electron microscopy: detection, characterisation and activities. Curr Nanosci. 2008;4(3):278-301.
89. Gatti AM, Tossini D, Gambarelli A, Montanari S, Capitani F. Investigation of the presence of inorganic micro- and nanosized contaminants in bread and biscuits by environmental scanning electron microscopy. Crit Rev Food Sci Nutr. 2009;49(3):275-282.

90. Male KB, Lachance B, Hrapovic S, Sunahara G, Luong JH. Assessment of cytotoxicity of quantum dots and gold nanoparticles using cell-based impedance spectroscopy. Anal Chem. 2008;80(14):5487-5493.

91. Tarantola M, Schneider D, Sunnick E, et al. Cytotoxicity of metal and semiconductor nanoparticles indicated by cellular micromotility. ACS Nano. 2009;3(1):213-222.

92. Khaydarov R, Khaydarov R, Gapurova O, Estrin Y. A novel method of continuous fabrication of aqueous dispersions of silver nanoparticles. IJNP. 2010;3(1):77-91.

93. Bhattacharya R, Mukherjee P. Biological properties of "naked" metal nanoparticles. Adv Drug Deliv Rev. 2008;60(11):1289-1306.

94. Benn TM, Westerhoff P. Nanoparticle silver released into water from commercially available sock fabrics. Environ Sci Technol. 2008;42(11):4133-4139.

95. Pallem VL, Stretz HA, Wells MJM. Evaluating aggregation of gold nanoparticles and humic substances using fluorescence spectroscopy. Environ Sci Technol. 2009;43(19):7531-7535.

96. Judy JD, Unrine JM, Bertsch PM. Evidence for biomagnification of gold nanoparticles within a terrestrial food chain. Environ Sci Technol. 2011;45(2):776-781.

97. Shukla R, Bansal V, Chaudhary M, Basu A, Bhonde RR, Sastry M. Biocompatibility of gold nanoparticles and their endocytotic fate inside the cellular compartment: a microscopic overview. Langmuir. 2005;21(23):10644-10654.

98. Hinther A, Vawda S, Skirrow RC, et al. Nanometals induce stress and alter thyroid hormone action in amphibia at or below North American water quality guidelines. Environ Sci Technol. 2010; 44(21):8314-8321.

99. AshaRani PV, Low Kah Mun G, Hande MP, Valiyaveettil S. Cytotoxicity and genotoxicity of silver nanoparticles in human cells. ACS Nano. 2009;3(2):279-290.

100. Stampoulis D, Sinha SK, White JC. Assay-dependent phytotoxicity of nanoparticles to plants. Environ Sci Technol. 2009;43(24): 9473-9479.
Nanotechnology, Science and Applications

\section{Publish your work in this journal}

Nanotechnology, Science and Applications is an international, peerreviewed, open access journal that focuses on the science of nanotechnology in a wide range of industrial and academic applications. It is characterized by the rapid reporting across all sectors, including engineering, optics, bio-medicine, cosmetics, textiles, resource sustainability

\section{Dovepress}

and science. Applied research into nano-materials, particles, nanostructures and fabrication, diagnostics and analytics, drug delivery and toxicology constitute the primary direction of the journal. The manuscript management system is completely online and includes a very quick and fair peer-review system, which is all easy to use. 